(c) 2018 - ISSN 1807-2577

\title{
Os efeitos da Punica granatum L. em diferentes concentrações sobre duas linhagens celulares: estudo in vitro
}

The effects of Punica granatum L. at different concentrations on two cell lines: in vitro study

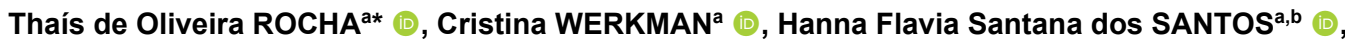 \\ Wagner de OLIVEIRA ${ }^{\mathrm{a}}$ (1), Sigmar de Mello RODE ${ }^{\mathrm{a}}$ (1) \\ aUNESP - Universidade Estadual Paulista, Instituto de Ciência e Tecnologia, Departamento Materiais Odontológicos e \\ Prótese, São José dos Campos, SP, Brasil \\ 'UNIP - Universidade Paulista, Instituto de Ciências da Saúde, São José dos Campos, SP, Brasil
}

\begin{abstract}
Como citar: Rocha TO, Werkman C, Santos HFS, Oliveira W, Rode SM. Os efeitos da Punica granatum L. em diferentes concentrações sobre duas linhagens celulares: estudo in vitro. Rev Odontol UNESP. 2020;49:e20200005. https://doi.org/10.1590/1807-2577.00520
\end{abstract}

\begin{abstract}
Resumo
Introdução: A Punica granatum L. (PG), utilizada como medicamento fitoterápico, apresenta propriedades terapêuticas, anti-inflamatórias e antioxidante. Embora diversos estudos já tenham sido realizados com este fitoterápico, seus possíveis efeitos citotóxicos nos tecidos humanos ainda não são claros. Objetivo: Avaliar a citotoxicidade da PG por meio de cultura celular com duas linhagens: fibroblastos humanos de mucosa oral (FLM) e células de carcinoma epidermoide oral humano (KB). Material e método: As células foram submetidas ao teste de viabilidade celular por 24 horas nas concentrações da PG 1\%, 0,50\%, 0,25\%, 0,125\%, $0,062 \%$ e $0,031 \%$, e aos testes de citotoxicidade celular em 4 horas, $1,3,5$ e 7 dias, em diferentes concentrações, realizados em triplicata. Foi utilizado um controle negativo (Triton 1\%) e um controle positivo sem o extrato de PG. Os dados obtidos foram submetidos à ANOVA $(p<0,05)$. Resultado: Foi possível observar que o extrato da PG possui efeitos inibitórios, apresentando-se maior nas células KB em relação às FLM. Os testes de citotoxicidade e viabilidade mostraram inibição e morte das células KB e FLM nas concentrações $1 \%, 0,50 \%$ e $0,25 \%$. Conclusão: $O$ efeito inibitório da PG foi dose-dependentes, mostrando-se maior nas células KB em relação às FLM.
\end{abstract}

Descritores: Punica granatum; fitoterapia; citotoxicidade; câncer.

\begin{abstract}
Introduction: Punica granatum L. (PG), used as a herbal medicine, has therapeutic, anti-inflammatory and antioxidant properties, although several studies have already been carried out with this herbal medicine, its possible cytotoxic effects on human tissues are still unclear. Objective: To evaluate the cytotoxicity of PG through cell culture with two strains: human oral mucosa fibroblasts (LFM) and human oral squamous cell carcinoma (KB) cells. Material and method: The cells were submitted to the cell viability test for 24 hours in the concentrations of PG $1 \%, 0.50 \%, 0.25 \%, 0.125 \%, 0.062 \%$ and $0.031 \%$ and the cell cytotoxicity tests in 4 hours, 1, 3, 5 and 7 days in different concentrations, performed in triplicate. A negative control (Triton 1\%) and a positive control without the PG extract were used. The data obtained were submitted to ANOVA ( $\mathrm{p}<0.05)$. Result: it was possible to observe that the PG extract has inhibitory effects, being higher in KB cells in relation to LFM. The cytotoxicity and viability tests showed inhibition and death of KB and FLM cells at concentrations of $1 \%, 0.50 \%$ and $0.25 \%$. Conclusion: The inhibitory effect of PG was dose dependent, showing itself to be greater in KB cells compared to LMB.
\end{abstract}

Descriptors: Punica granatum; phytotherapy; cytotoxicity; cancer. 


\section{INTRODUÇÃO}

As doenças não transmissíveis são atualmente consideradas a maior causa de morte no mundo e doenças, como câncer, ajudam a alavancar esses resultados epidemiológicos, sendo esta a primeira ou a segunda causa de morte antes dos 70 anos, em 91 dos 172 países ${ }^{1}$. 0 desafio financeiro é outra questão elencada na problemática do câncer, pois estima-se que os gastos com o tratamento aumentem globalmente 458 bilhões de dólares até $2030^{2}$.

A importância dos alimentos para a saúde é reconhecida desde Hipócrates. O uso de substâncias comestíveis, em especial, a derivada de plantas, para o tratamento das doenças, tem se verificado ao longo desse último século. Mas essa associação da alimentação com a saúde é observada a datar desde o século $\mathrm{V}$ a.C. Os Sistemas Medicinais em várias partes do mundo, sobretudo na América do Sul e em países, como o Brasil, utilizam as plantas medicinais no tratamento das patologias ${ }^{3-6}$. Alguns frutos, como a romã, são conhecidos por sua atividade antioxidante, antiteratogênica, antiproliferativa e anti-inflamatória, devido aos bioativos que os compõem ${ }^{5}$. Em razão desse fato, há interesse dos pesquisadores sobre as evidências científicas das propriedades desse fruto.

A romã, que recebe o nome científico de Punica granatum, é um fruto originário da Pérsia e foi cultivado no Norte da Índia e na região do Mediterrâneo desde a Antiguidade. Atualmente, também é cultivada no Norte da África, na África tropical, na Europa, na América do Norte e na América do Sul6.

As propriedades terapêuticas, anti-inflamatórias e antioxidante, são atribuídas ao seu elevado teor de taninos hidrolisáveis e antocianinas. Quando comparado com a atividade de outros antioxidantes, como a da Vitamina E, do $\beta$-caroteno e do ácido ascórbico, os antioxidantes da romã se destacam, pois possuem uma significante ação contra vários tipos de radicais livres e uma ampla gama de polifenóis ${ }^{6,7}$.

A atividade anticancerígena da Punica granatum está supostamente associada a mecanismos antioxidativos, antigenotóxicos, antiproliferativos, anti-invasivos e antimetastáticos, e à indução da apoptose pela regulação positiva das proteínas p21 e p27, além da modulação das proteínas $\mathrm{Bcl}-2$ e da suprarregulação da rede $c y c l i n-c d k^{8,9}$. Contudo, o papel citotóxico ainda não é tão claro. Com isso, a proposta deste estudo foi avaliar a citotoxicidade da Punica granatum L. sobre duas linhagens celulares, uma de fibroblastos humanos de mucosa oral e outra de células cancerígenas.

\section{MATERIAL E MÉTODO}

A toxicidade da Punica granatum L. (PG) foi avaliada, utilizando cultura de células de fibroblastos humanos de mucosa oral (FLM), obtida por meio de cultura primária originada de material de explante de doador voluntário, e uma linhagem de células cancerígenas, Carcinoma Epidermoide Oral Humano ATCC CCL-17 (KB), pertencentes a uma linhagem comercial adquirida através do Instituto Adolf Lutz, as quais são mantidas no banco de células do Laboratório de Bio Odontologia da Universidade Ibirapuera.

O objetivo deste trabalho foi investigar in vitro, utilizando análise quantitativa e qualitativa, os efeitos da Punica granatum L., em diferentes concentrações, sobre duas linhagens de células: fibroblastos de mucosa bucal humana (FLM) e uma linhagem de células cancerígenas (KB). As placas contendo as células e o extrato foram incubadas em estufa a $37^{\circ} \mathrm{C}$ com $5 \% \mathrm{CO}_{2}$.

Os testes foram realizados levando-se em conta a viabilidade e a citotoxicidade das células quando em contato com a PG em diferentes concentrações, e os testes mantiveram o protocolo de triplicata. 0 presente estudo foi aprovado pelo Comitê de Ética em Pesquisa sob o número 298/07. 


\section{Grupos Experimentais}

Na primeira etapa, um estudo-piloto foi realizado com teste experimental de viabilidade por 24 horas, com diferentes concentrações e quantidade de polifenóis, para avaliar em quais concentrações seria observada a morte celular. As porcentagens do extrato foram testadas nas células, começando pela concentração total e sendo avaliadas as diluições. As porcentagens usadas no estudo foram as que possibilitaram a permanência das células vivas após $24 \mathrm{~h}$ de exposição ao extrato de Punica granatum (Tabela 1).

Tabela 1. Concentrações e quantidade de Punica granatum L. com respectiva quantidade de polifenóis testados para definir as concentrações a serem utilizadas nos testes de viabilidade

\begin{tabular}{cccc}
\hline Concentrações testadas & Volume (mL) de PG & $\begin{array}{c}\text { Quantidade Polifenóis } \\
(\%)\end{array}$ & $\begin{array}{c}\text { Morte celular no teste- } \\
\text { piloto }\end{array}$ \\
\hline $50 \%$ & 0,5 & 0,3 & Sim \\
$25 \%$ & 0,25 & 0,15 & Sim \\
$12,50 \%$ & 0,125 & 0,075 & Sim \\
$10 \%$ & 0,1 & 0,06 & Sim \\
$7,50 \%$ & 0,075 & 0,045 & Sim \\
$5 \%$ & 0,05 & 0,03 & Sim \\
$2,50 \%$ & 0,025 & 0,015 & Sim \\
$1 \%$ & 0,01 & 0,006 & Não \\
$0,80 \%$ & 0,008 & 0,0048 & Não \\
$0,50 \%$ & 0,005 & 0,005 & Não \\
$0,25 \%$ & 0,0025 & 0,003 & Não \\
$0,125 \%$ & 0,00125 & 0,0015 & Não \\
$0,062 \%$ & 0,00062 & 0,000372 & Não \\
$0,031 \%$ & 0,00031 & 0,000186 & Não \\
\hline
\end{tabular}

Para obtenção das soluções padronizadas de PG utilizadas para os testes de citotoxicidade, $0,1 \mathrm{mg}$ do material liofilizado foi acondicionado em tubos com $6 \mathrm{~g}$ cada um e mantidos sob vácuo em dessecador (Vidrolabor - São Paulo-SP, Brasil) e adicionado a $10 \mathrm{~mL}$ de meio de cultivo, sendo homogeneizados em vórtex (Quimis Q-220-B - São Paulo-SP, Brasil) até a dissolução total do soluto. Foram preparadas soluções contendo o equivalente a 12,5 mg de extrato de PG em cada $10 \mathrm{~mL}$ do meio de cultura. Em seguida, as soluções foram colocadas em seringas descartáveis estéreis (DB Plastipak - São Paulo-SP, Brasil) e passadas em filtro com poros de 0,22 $\mu \mathrm{m}$ (Corning Inc.), sendo conservadas em geladeira a $4{ }^{\circ} \mathrm{C}$. As concentrações estabelecidas de acordo com as respostas obtidas foram de seis diferentes concentrações, sendo então estabelecidos grupos experimentais com 1\%, 0,50\%, 0,25\%, 0,125\%, 0,062\% e 0,031\% PG (Figura 1). 


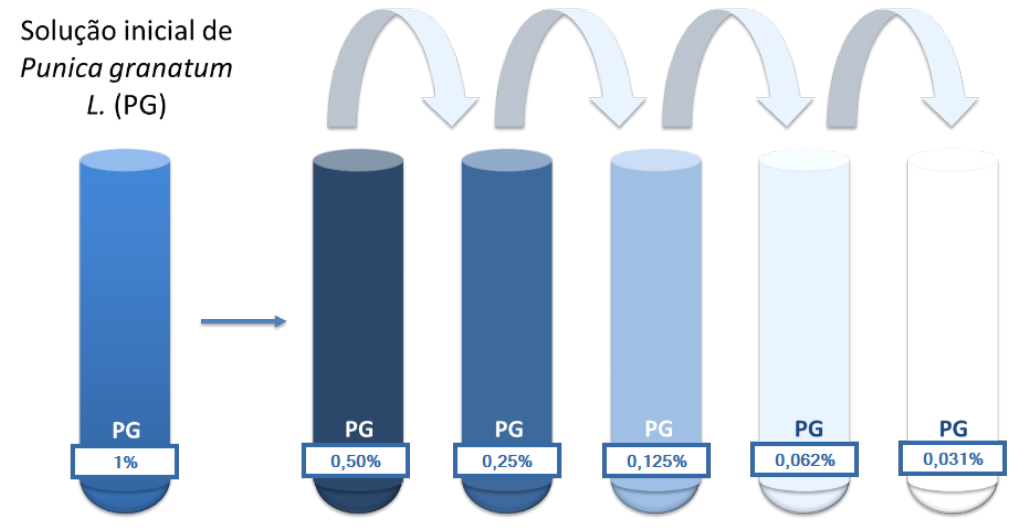

Grupos testes com diluições de PG

Figura 1. Solução base e diluições preconizadas de PG para os testes de viabilidade. Células cancerígenas $(\mathrm{KB})$, fibroblastos de mucosa bucal humana (FLM).

Além das concentrações propostas, o controle positivo e o controle negativo foram usados nos testes. Como controle positivo, foi usado o meio de cultivo de cada tipo celular acrescido de SBF $10 \%$ e sem o extrato de PG; já para o controle negativo, foi utilizada a solução de Triton $1 \%$. A viabilidade celular foi observada no período de $24 \mathrm{~h}$ e a citotoxicidade celular, no período de sete dias.

\section{Ensaio de Viabilidade das Células}

0 ensaio de viabilidade celular utilizou $6 \times 10^{4}$ células em cada poço (placa de 96 poços) com $\mathrm{n}=3$ ( $\mathrm{n}=$ número de poços) para todos os grupos que foram classificados de acordo com sua concentração de $\mathrm{PG}$, incluindo os grupos controles positivo ( $\mathrm{C}+$ ) e negativo (C-), tanto para células FLM como KB. As soluções com concentrações de 1\%, 0,50\%, 0,25\%, 0,125\%, 0,062\% e 0,031\% PG foram acrescidas aos poços e foram incubadas por $24 \mathrm{~h}$ em estufa a $37^{\circ} \mathrm{C}$ com $5 \%$ de $\mathrm{CO}_{2}$. Após período de incubação, foram coradas com Resazurina (RZ) para avaliação da espectrofotometria óptica. $\mathrm{O}$ espectrofotômetro UVM 340 (Asys Hitech $\mathrm{GmbH}$ ) foi usado para leitura de absorbância no comprimento de onda de $570 \mathrm{~nm}$.

\section{Ensaio de Citotoxicidade das Células}

0 ensaio de citotoxicidade foi realizado em placas de 24 poços com $4 \times 10^{4}$ células. As concentrações do extrato de PG foram 1\%, 0,50\%, 0,25\% e 0,062\%. As concentrações utilizadas no teste de citotoxicidade basearam-se em resultados previamente obtidos nos testes de viabilidade.

A citotoxicidade celular foi analisada em cinco períodos diferentes $(4 \mathrm{~h}, 24 \mathrm{~h}, 3$ dias, 5 dias e 7 dias). Após cada tempo designado, cada placa foi preparada para a coloração com Resazurina e a quantificação pelo espectrofotômetro UVM 340 foi empregado para leitura de absorbância nos comprimentos de onda de $570 \mathrm{~nm}$.

\section{Análise Estatística}

As hipóteses estatísticas foram avaliadas previamente à análise estatística, sendo que nenhum dos pressupostos foram violados. Dessa maneira os dados quantitativos foram submetidos à Análise de Variância ANOVA ( $\mathrm{p}<0,05)$. 


\section{RESULTADO}

Por meio das análises de comparações múltiplas de Tukey, foi possível observar diferenças na viabilidade celular em diferentes concentrações do extrato de PG em KB entre os grupos 1,00\% e $0,125 \%, 1,00 \%$ e $0,062 \%$, e também entre $1,00 \%$ e $0,031 \%$ ( $<<0,05)$. Porém, não foi observada diferença estatisticamente significante na viabilidade de células FLM em contato com as diferentes concentrações (Figura 2).

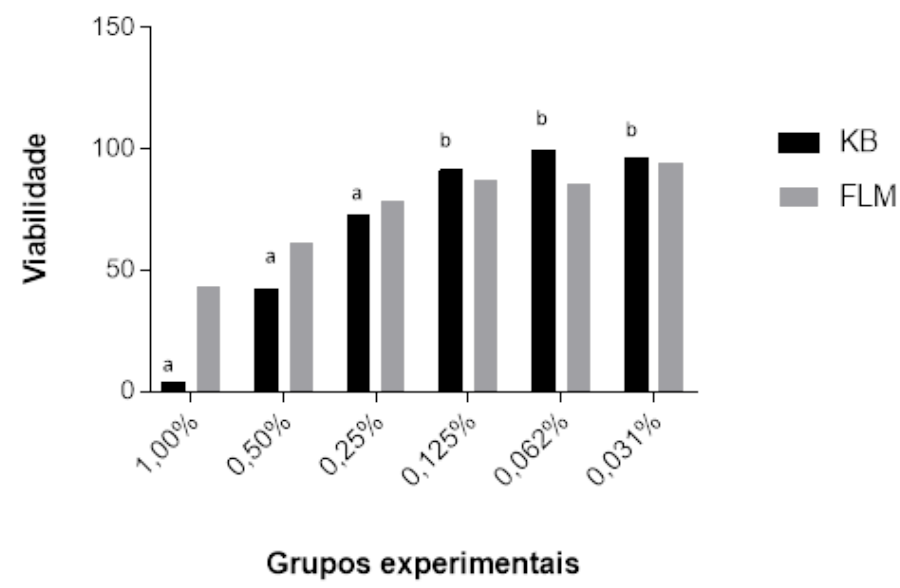

Figura 2. Gráfico demonstrativo das diferenças estatísticas das concentrações de PG nas diferentes linhagens celulares do estudo. As concentrações de PG foram representadas no eixo horizontal em ordem decrescente de concentração para as diferentes linhagens celulares utilizadas. Células cancerígenas (KB), fibroblastos de mucosa bucal humana (FLM).

0 teste de viabilidade permitiu observar sobrevivência de mais de $70 \%$ das células FLM e KB em baixas concentrações de PG $(0,031 \% ; 0,062 \% ; 0,125 \% ; 0,25 \%)$. Já na concentração de $0,50 \%$, ocorreu uma redução significativa da quantidade de células. Na concentração de $1 \%$ de PG, foi observada diminuição de cerca de $40 \%$ das células FLM e destruição significativa para as células KB. Os resultados estão expressos na Figura 3.

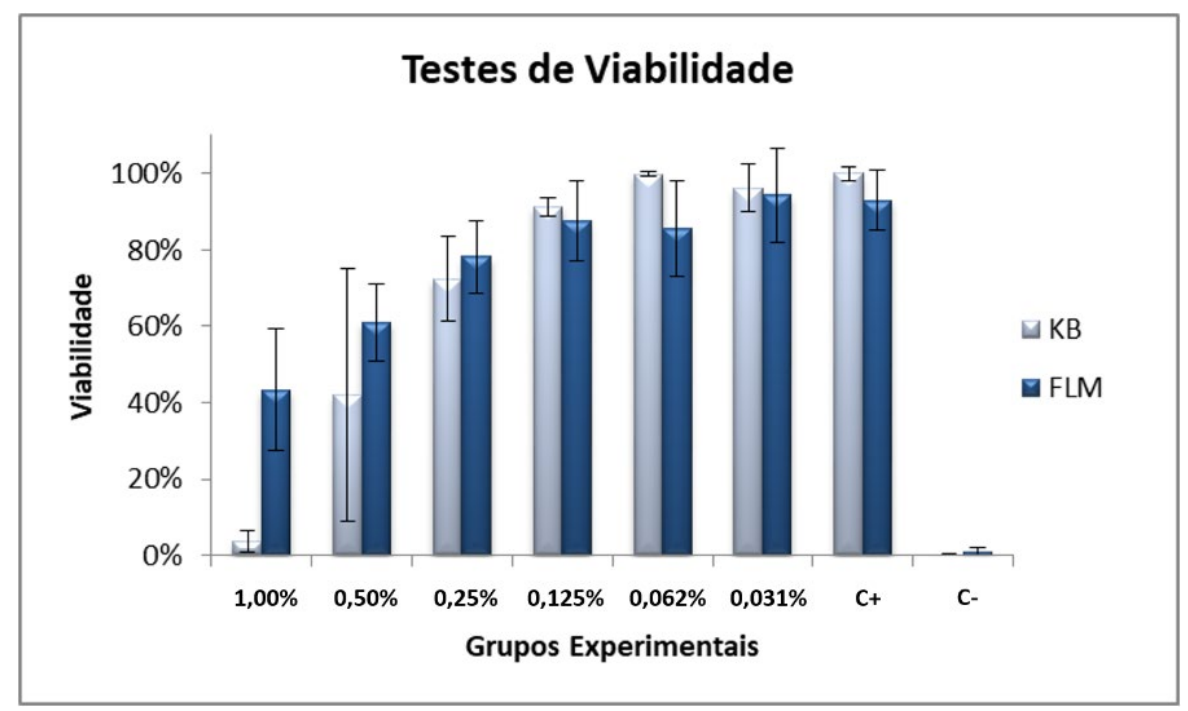

Figura 3. Gráfico demonstrativo da viabilidade para as células FLM e KB. Os grupos experimentais foram descritos no eixo horizontal em ordem decrescente de concentração, no qual $(C+)$ representa o controle positivo e (C-), o controle negativo. Células cancerígenas (KB), fibroblastos de mucosa bucal humana (FLM). 
0 teste de viabilidade para as células FLM e KB nas concentrações de 0,25\%, 0,50\% e 1\% apresentou, no período de 4 horas, uma redução do número de células metabolicamente ativas e morte da maioria das células no primeiro dia de contato das células com o extrato. Contudo, o grupo $0,062 \%$ mostrou nível de citotoxicidade muito próximo ao grupo controle positivo (C+), sem diferença estatística significativa. De modo geral, a comparação entre células e períodos analisados possibilitou observar que, após $4 \mathrm{~h}$ de contato entre as células e a PG, ocorreu redução do número celular proporcional ao aumento da concentração de PG. A diminuição foi significante para a concentração de 0,50\% e 1\% de PG, sendo maior para as células KB (Figuras 4 e 5).

No dia 1, o contato entre células e meio contendo extrato de PG apresentou morte de grande quantidade das células nas concentrações de 1\%, 0,50\% e 0,25\% de PG, com valores da reação de RZ semelhantes aos do grupo controle negativo. As células KB foram mais afetadas que as células FLM, porém a diferença entre os valores de sobrevivência só foi significativa na concentração de 1\%.

A sobrevivência celular com três dias contendo o extrato de PG demonstrou citotoxicidade contínua das células presentes no grupo $0,062 \%$, que acompanhou o ritmo de crescimento das células do grupo controle positivo.

Nas concentrações de 1\%, 0,50\% e 0,25\%, houve grande destruição dos dois tipos celulares sem diferença estatística entre os grupos

Com cinco dias de teste, foi possível constatar baixa taxa de citotoxicidade das células no grupo $0,062 \%$ de PG, que apresentam crescimento semelhante ao das células controle positivo. Nos grupos com concentração $1 \%, 0,50 \%$ e $0,25 \%$, foi observada morte de praticamente todas as células, sem diferença entre os grupos. Com sete dias de teste, foi observado comportamento semelhante ao dos três e cinco dias.

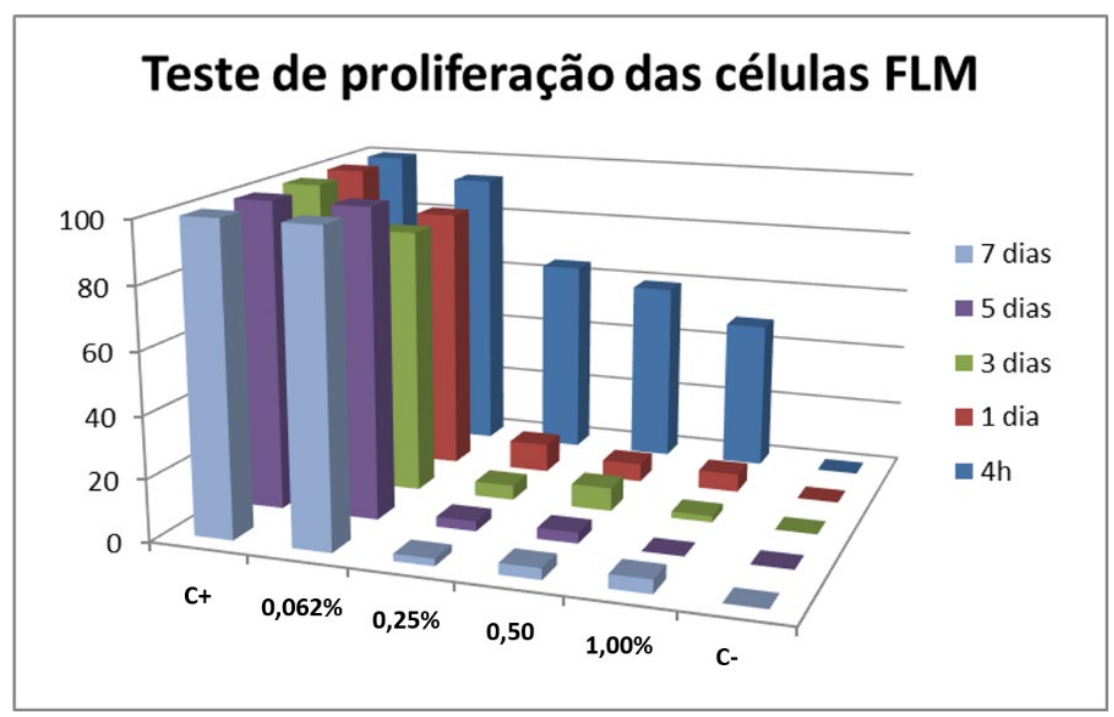

Figura 4. Gráfico representativo dos valores de citotoxicidade das células FLM nos períodos de 4 horas, 1, 3, 5 e 7 dias. Os grupos experimentais foram descritos no eixo horizontal em ordem crescente de concentração, o item $(\mathrm{C}+$ ) representa o controle positivo e (C-) controle negativo; a proliferação foi avaliada em diferentes períodos a fim de comparar os resultados obtidos para células FLM. Células cancerígenas

(KB), fibroblastos de mucosa bucal humana (FLM). 


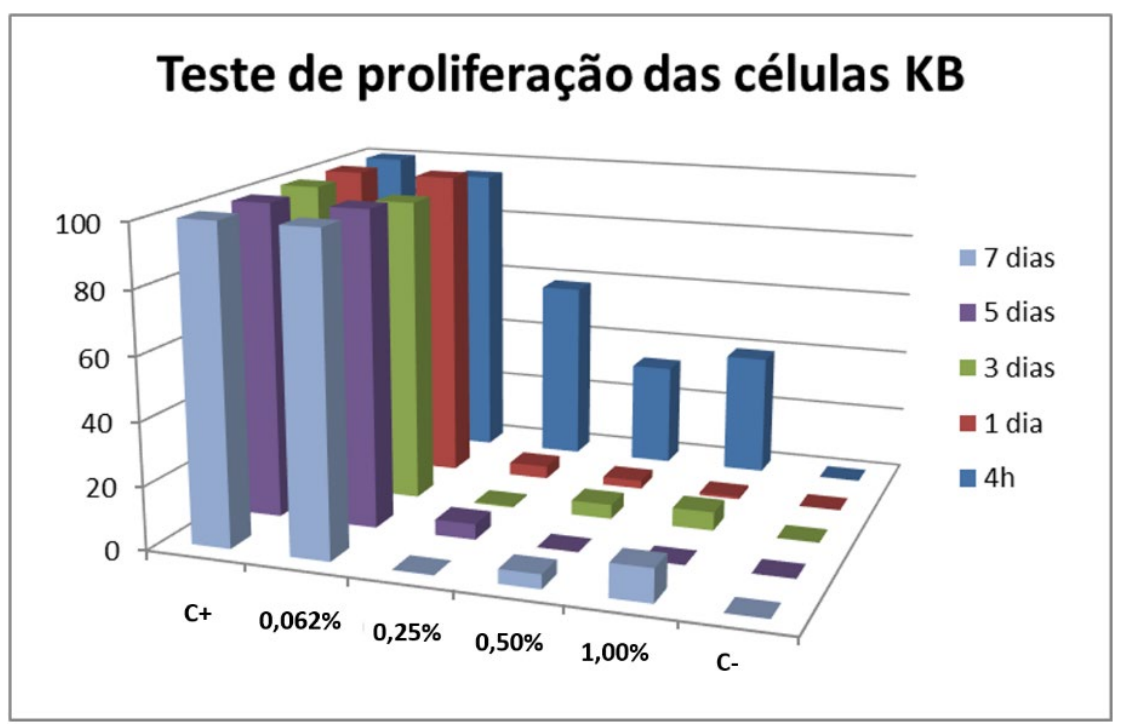

Figura 5. Gráfico representativo dos valores de citotoxicidade das células KB nos períodos de 4 horas, 1, 3, 5 e 7 dias. Os grupos experimentais foram descritos no eixo horizontal em ordem crescente de concentração; o item $(\mathrm{C}+)$ representa o controle positivo e (C-) controle negativo; a proliferação foi avaliada em diferentes períodos a fim de comparar os resultados obtidos para células KB. Células cancerígenas

$(\mathrm{KB})$, fibroblastos de mucosa bucal humana (FLM).

\section{DISCUSSÃO}

A busca por desenvolvimento de produtos não tóxicos, acessíveis e eficazes no combate ao câncer tem crescido, uma vez que os medicamentos quimioterápicos existentes estão associados a respostas clínicas inconsistentes, desenvolvimento de resistência, recorrência e progressão da patologia ${ }^{10}$. A medicina moderna busca por moléculas ativas purificadas como pistas terapêuticas. No entanto, muitas plantas que são estudadas pela medicina tradicional já são de conhecimento e usadas há muitos anos pela medicina tradicional chinesa, indiana e árabe, para o tratamento de diversas doenças ${ }^{11}$. Alguns frutos são usados como fitoterápicos em medicinas alternativas como tratamento de diversas patologias, por possuírem ações multidirecionadas e poucos efeitos colaterais ${ }^{10}$.

O experimento, ao avaliar a toxicidade da Punica granatum L., observou, no teste de viabilidade, que as células $\mathrm{KB}$ apresentaram-se mais sensíveis ao extrato, demonstrando a toxicidade do extrato, já que apresentaram menor taxa de viabilidade. Essa observação não foi constatada no grupo de células FLM com a mesma concentração. Esse fato que corrobora relatos encontrados na literatura, que evidenciam a diminuição da viabilidade e da proliferação celular em células cancerígenas após a exposição a fitoterápicos ${ }^{12}$. Isto pode ser também atribuído ao efeito antiproliferativo do extrato da romã sobre as células cancerígenas ${ }^{6,13,14}$.

0 efeito antiproliferativo também foi constatado ao avaliar o teste de citotoxicidade da PG nas concentrações 1\%, 0,50\% e 0,25\% nas primeiras 24 horas. Após esse período, houve morte da grande maioria das células, porém as células KB apresentaram índices de sobrevivência menores que as FLM, como também é referido no trabalho de Li et al. ${ }^{15}$. Contudo, a concentração de $0,062 \%$ apresentou maior sobrevivência celular com valores semelhantes aos do grupo controle positivo, com 99,83\% de viabilidade celular. E as células FLM, apesar de não apresentarem diferença estatística, tinham menores taxas de sobrevivência $(85,59 \%)$ em comparação às células KB, mostrando uma redução das células viáveis.

0 estudo de Khwairakpam et al. ${ }^{10}$ descreve PG com importantes propriedades anticancerígenas e, em diversas partes da planta, já foram identificadas diferentes classes de fitoquímicos, como elangitaninos, ligninas, flavonoides, galotaninos lipídeos, triterpenos, ácidos 
orgânicos e ácidos fenólicos tendo eficácia extremamente antioxidante exclusiva da romã. Note-se que esses efeitos podem explicar alguns achados do nosso estudo ${ }^{16}$. Neste, foi possível observar que o extrato da PG possui efeitos citotóxicos com efeitos inibitórios para proliferação celular nas células KB em relação às FLM durante os testes realizados ${ }^{17,18}$.

\section{CONCLUSÃO}

Conclui-se que houve inibição e morte das células KB e FLM nas concentrações 1\%, 0,50\% e 0,25\%, demonstrando o efeito inibitório da PG dose-dependente. Entretanto, observou-se maior ação inibitória em células KB em relação às FLM, com exceção da concentração de 0,062\%, na qual as células FLM foram mais afetadas. A partir dos resultados obtidos, podemos observar a relevância biológica da Punica granatum diante dos resultados in vitro.

\section{REFERÊNCIAS}

1. Bray F, Ferlay J, Soerjomataram I, Siegel RL, Torre LA, Jemal A. Global cancer statistics 2018:

GLOBOCAN estimates of incidence and mortality worldwide for 36 cancers in 185 countries. CA Cancer J Clin. 2018 Nov;68(6):394-424. http://dx.doi.org/10.3322/caac.21492. PMid:30207593.

2. Ghose $S$, Radhakrishnan V, Bhattacharya S. Ethics of cancer care: beyond biology and medicine. Ecancermedicalscience. 2019 Mar;13:911. http://dx.doi.org/10.3332/ecancer.2019.911. PMid:31123494.

3. Holetz FB, Pessini GL, Sanches NR, Cortez DAG, Nakamura CV, Dias BP Fo. Screening of some plants used in the Brazilian folk medicine for the treatment of infectious diseases. Mem Inst Oswaldo Cruz. 2002 Oct;97(7):1027-31. http://dx.doi.org/10.1590/S0074-02762002000700017. PMid:12471432

4. Ferreira SRG. Nutrição não sai de moda. Arq Bras Endocrinol Metabol. 2009 Jul;53(5):483-4. http://dx.doi.org/10.1590/S0004-27302009000500001. PMid:19768239.

5. Nascimento BJ Jr, Tínel LO, Silva ES, Rodrigues LA, Freitas TON, Nunes XP, et al. Avaliação do conhecimento e percepção dos profissionais da estratégia de saúde da família sobre o uso de plantas medicinais e fitoterapia em Petrolina-PE, Brasil. Rev Bras Plantas Med. 2016 Mar;18(1):57-66. http://dx.doi.org/10.1590/1983-084X/15_031.

6. Sharma P, McClees SF, Afaq F. Pomegranate for prevention and treatment of cancer: an update. Molecules. 2017 Jan;22(1):177. http://dx.doi.org/10.3390/molecules22010177. PMid:28125044.

7. Shaygannia E, Bahmani M, Zamanzad B, Rafieian-Kopaei M. A review study on Punica granatum L. J Evid Based Complementary Altern Med. 2016 Jul;21(3):221-7. http://dx.doi.org/10.1177/2156587215598039. PMid:26232244.

8. Turrini E, Ferruzzi L, Fimognari C. Potential effects of pomegranate polyphenols in cancer prevention and therapy. Oxid Med Cell Longev. 2015;2015:938475. http://dx.doi.org/10.1155/2015/938475. PMid:26180600.

9. Mandal A, Bishayee A. Mechanism of breast cancer preventive action of pomegranate: disruption of estrogen receptor and Wnt/ $\beta$-catenin signaling pathways. Molecules. 2015 Dec;20(12):22315-28. http://dx.doi.org/10.3390/molecules201219853. PMid:26703530.

10. Khwairakpam AD, Bordoloi D, Thakur KK, Monisha J, Arfuso F, Sethi G, et al. Possible use of Punica granatum (Pomegranate) in cancer therapy. Pharmacol Res. 2018 Jul;133:53-64. http://dx.doi.org/10.1016/j.phrs.2018.04.021. PMid:29729421.

11. Joshi C, Patel P, Kothari V. Anti-infective potential of hydroalcoholic extract of Punica granatum peel against gram-negative bacterial pathogens. F1000 Res. 2019 Apr;8:70. http://dx.doi.org/10.12688/f1000research.17430.2. PMid:30828441. 
12. Semwal DK, Semwal RB, Combrinck S, Viljoen A. Myricetin: a dietary molecule with diverse biological activities. Nutrients. 2016 Feb;8(2):90. http://dx.doi.org/10.3390/nu8020090. PMid:26891321.

13. Seeram NP, Adams LS, Henning SM, Niu Y, Zhang Y, Nair MG, et al. In vitro antiproliferative, apoptotic and antioxidant activities of punicalagin, ellagic acid and a total pomegranate tannin extract are enhanced in combination with other polyphenols as found in pomegranate juice. J Nutr Biochem. 2005 Jun;16(6):360-7. http://dx.doi.org/10.1016/j.jnutbio.2005.01.006. PMid:15936648.

14. Syed DN, Chamcheu JC, Adhami VM, Mukhtar H. Pomegranate extracts and cancer prevention: molecular and cellular activities. Anticancer Agents Med Chem. 2013 Oct;13(8):1149-61. http://dx.doi.org/10.2174/1871520611313080003. PMid:23094914.

15. Li Y, Yang F, Zheng W, Hu M, Wang J, Ma S, et al. Punica granatum (pomegranate) leaves extract induces apoptosis through mitochondrial intrinsic pathway and inhibits migration and invasion in non-small cell lung cancer in vitro. Biomed Pharmacother. 2016 May;80:227-35. http://dx.doi.org/10.1016/j.biopha.2016.03.023. PMid:27133061.

16. Saeed M, Naveed M, BiBi J, Kamboh AA, Arain MA, Shah QA, et al. The Promising pharmacological effects and therapeutic/medicinal applications of Punica granatum L. (Pomegranate) as a functional food in humans and animals. Recent Pat Inflamm Allergy Drug Discov. 2018;12(1):24-38. http://dx.doi.org/10.2174/1872213X12666180221154713. PMid:29473532.

17. Shirode AB, Bharali DJ, Nallanthighal S, Coon JK, Mousa SA, Reliene R. Nanoencapsulation of pomegranate bioactive compounds for breast cancer chemoprevention. Int J Nanomedicine. 2015 Jan;10:475-84. http://dx.doi.org/10.2147/IJN.S65145. PMid:25624761.

18. Badawi NM, Teaima MH, El-Say KM, Attia DA, El-Nabarawi MA, Elmazar MM. Pomegranate extractloaded solid lipid nanoparticles: design, optimization, and in vitro cytotoxicity study. Int J Nanomedicine. 2018 Mar;13:1313-26. http://dx.doi.org/10.2147/IJN.S154033. PMid:29563789.

\section{CONFLITOS DE INTERESSE}

Os autores declaram não haver conflitos de interesse.

\section{*AUTOR PARA CORRESPONDÊNCIA}

Thaís de Oliveira Rocha, UNESP - Universidade Estadual Paulista, Instituto de Ciência e Tecnologia, Departamento Materiais Odontológicos e Prótese, Av. Eng. Francisco José Longo, 777, Jardim São Dimas, 12245-000 São José dos Campos - SP, Brasil, e-mail: thais.rocha@unesp.br

Recebido: Janeiro 30, 2020

Aprovado: Maio 28, 2020 